\title{
Analysis of historical cartography and data presentation for an educational purpose: The case of the historical centre of Vimercate
}

\author{
Dina Jovanović $^{\mathrm{a}, *}$, Daniela Oreni ${ }^{\text {a }}$, Stefano Della Torre ${ }^{\mathrm{a}}$, Rossella Moioli ${ }^{\mathrm{a}}$ \\ ${ }^{a}$ Department of Architecture, Built environment and Construction Engineering, Politecnico di Milano, Italy. \\ dina.jovanovic@polimi.it; daniela.oreni@polimi.it; stefano.dellatorre@polimi.it; rossella.moioli@polimi.it \\ * Corresponding author
}

\begin{abstract}
Founded by Romans, Vimercate had an important geographical position in Lombardy. Layers of history are visible throughout the town, yet there is the inconsistency of historical data and neglect of the historical centre in the past decades. Only recently researchers and professors from Politecnico di Milano pointed out the importance of studying layers of history in the built environment. In the past years, Vimercate was used as an example for students from masters and bachelor courses in preservation studios. This is where the idea for the master's thesis was developed which focuses on the collection, digitalisation and investigation of primary historical cartography and then other historical documents. Historical cartography can offer extensive knowledge about the past of this town and it is one of the main sources of information. For the creation of the project was selected free and open-source software QGIS where the selected historical maps were vectorised, compared and investigated. A new understanding of the development of the city was studied and some discoveries appeared. Effective application of the thesis project started in the courses of Architectural preservation studio at Politecnico di Milano. This was followed by the interest of citizens in the project who were actively participated in the creation of the same. Other stakeholders showed interest in involving in future developments. The thesis found its application in didactic activities of students and pupils.
\end{abstract}

Keywords: Vimercate, HGIS, historical cartography, participatory activities, teaching tool, data representation

\section{Introduction}

Vimercate is in the province Monza and Brianza, in the region Lombardy and still maintains some features of the ancient Roman village in the disposition of the urban plot. Previously called Vicus Mercati, it was in a neuralgic crossing point between roman roads connecting Milan to the Alps and the citadel of Bergamo (Figure 1) (Cazzani 1975). Although the ancient historiography does not report any data, the archaeological discoveries let us hypnotize that the urban development of the city happened mainly around the I century BC as a Roman colony incorporated in Mediolanum ${ }^{1}$ (Vergani 1994). Town's evolution is undoubtedly related to the significant religious administrative and commercial functions carried out in past centuries, especially in the Middle Ages when in 1079 $\mathrm{AD}$ it passed from vicus ${ }^{2}$ to burgus $^{3}$ (Venturelli and Vergani 1998; Dossi and Crippa 1992).

Vimercate is a city with fruitful history but there is a lack of data and inconsistency of understanding what happened through the time with the city. Neglected for many decades the homogeneity and authenticity of the historical city centre is violated but the traces of the past are however visible and could be investigated through historical cartography and documents. Vimercate only recently got the attention it deserves from individual researchers and institutions. More recently, one of the biggest drivers in developing awareness and interest in the history of Vimercate is Politecnico di Milano (Della Torre, Moioli, and Cantini 2018).

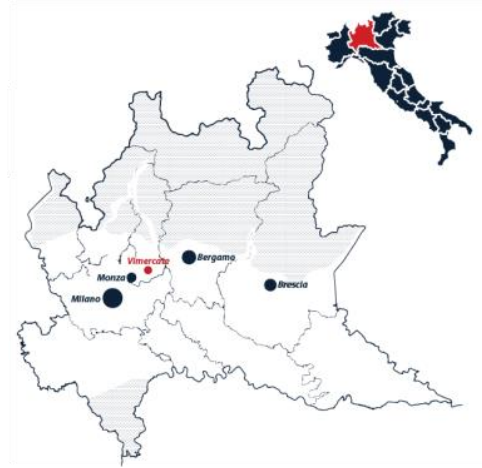

Figure 1. The geographical position of Vimercate; Author Jovanovic, D.

This triggered the author to create a master's thesis on this topic. Furthermore, the paper is created based on the thesis presented at Politecnico di Milano. The thesis collected, analysed and presented historical and contemporary data at the urban scale, in the span of almost three hundred years, from 1721 until 2019. The program used was QGIS which has many advantages because it is open and free source software available to everyone, but it has also limits because it is not available online and the project is stashed

\footnotetext{
${ }^{1}$ The Latin name for Milan

${ }^{2}$ Eng. village 
in the personal computer which requests further development of the WebGIS platform.

Nevertheless, the importance and influence of the thesis gradually were showed especially after graduation, and it was actively used in the education of students and citizens. The main goal was to create a database to provide accessible maps and data for the students at Politecnico di Milano, which will be used as a source of knowledge and will host their further contributions. Involving other stakeholders as administration and citizens will engirdle the purpose of the project.

\section{Related work}

One of the main inspirations for the thesis was a project of Treviso Urbs Picta ${ }^{4}$ developed between 2012 and 2013. The research made in Treviso starts with the analysis of facades, their styles and iconography of the houses and other buildings decorated in the period between the XIII and XX century (Riscica and Voltarel 2017). Visualizing Venice $^{5}$ is another project with a similar aim that started in 2009. Their research is based on archival sources from which is generated animations and a 3D model of Venice that aims to stress the question of urban change and transformation (Huffman, Giordano, and Bruzelius 2017).

The Project "World Heritage City Preservation Management"6 in Cuenca in Ecuador applies $\mathrm{HUL}^{7}$ approach. They are trying to activate a wide spectrum of new actors who are involved in the management of the city, from the public to private participation groups. They evaluated the state of conservation of the city of Cuenca, identifying the urban, architectural, touristic, landscape, economic, social, and spatial impact on the cultural heritage values. In the end, involving all stakeholders, academics, students and experts, but especially the citizen, for collective value assessment gave the best results (Roders and Bandarin 2019). "Mappatura culturale della città vecchia"8, is the overall result of the subprojects 2 and 3 of the European project "Civis Ambiente" of mapping Genova. They wanted to provide an original planning support tool for the historic city centre. Mapping finished in 1999.

Book "Microanalisi di una città"9 give us insight into property and use of the houses of the walled city of Como from the XVI century until the XIX century. More than thirty-five years ago, authors did not have the advanced technological tools that we have today, nevertheless, they provided the inexhaustible amount of data that profoundly analyse historical cadastres, descriptions and drawings of built heritage (Gianoncelli and Della Torre 1984).

\footnotetext{
${ }^{4}$ https://trevisourbspicta.fbsr.it/

${ }^{5} \mathrm{http}: / /$ www.visualizingvenice.org/visu/

${ }^{6}$ https://gohulsite.files.wordpress.com/2016/11/2014-mayworkshop.pdf

${ }^{7}$ Historical Urban Landscape
}

Other examples are more oriented to mobile apps and touristic discovering. Free app Hidden Florence ${ }^{10}$ allows you to download stories of different historical characters and to follow their stories that will lead you through Florence with a rich history, architecture and art that are linked to the selected sites (Nevola and Rosenthal 2016).

These examples are using historical cartography for education and participatory public engagement in cultural heritage and were an important input for the thesis development. Firstly, all of them are transparent and freely accessible sources of data to be consulted online. Secondly, using historical maps to share knowledge about cultural heritage with experts and non-experts appeared to be an effective way of involving them, and they start using historical maps not just as an artistic artefact but also as a valuable source of information for a wide range of application, from architecture to territorial management, hazard predictions, land coverage survey, planning, and to archaeology and socio-political research.

\section{Methodology}

The collection of the cartographic and chorographic material was processed in the Geographic Information System. Overlapping and comparing data is the only way to create a timeline of urban development. Integration of these data into digital GeoDB ${ }^{11}$ can increase the efficiency in managing and tracking changes in the built environments (Brumana et al. 2010).

The thesis is oriented on searching, organizing, filtrating, and presenting all collected data. Computer software can wield historical and contemporary maps, documentation, photos and projects inside one system. Additionally, by layering and visualizing these data, GIS could be used as a tool in decision-making and problem-solving processes. Specifically, the thesis is oriented to the Historical Geographic Information System (HGIS) that can store, analyse and display data of the historical geographies and track changes through time. Techniques that are used in the HGIS are:

- Digitalising and georeferencing historical maps.

- Vectorizing historical maps.

- Digitalising historical metadata (e.g. census, parish records, cadastres) which provide the third dimension to the map thus the textual data could be visually presented.

The database is imagined as an interactive map that can educate, inform and point out the possible methods for preservation, maintenance and management of built cultural heritage. The software used for this project is a

\footnotetext{
${ }^{8}$ http://civis.comune.genova.it/mappatura.htm

${ }^{9}$ Engl. Microanalysis of a city

${ }^{10}$ https://hiddenflorence.org/

${ }^{11}$ Geographical Database
} 
free and open QGIS program, but in the future, the map should be also accessible online.

\section{Data Collection}

Collecting the material was a primary step. One of the most important things is knowing the credibility and truthfulness of the source from where information is coming. All material analysed is collected from:

1. Historical and modern cartography:

- Archivio di Stato di Milano (ASMi) ${ }^{12}$

- Geoportale della Lombardia ${ }^{13}$

- Sportello Telematico Unificato del Comune di Vimercate $^{14}$

- MAPIRE project ${ }^{15}$

- Istituto Geografico Militare ${ }^{16}$

- Astronomi di Brera (from ASMi) ${ }^{17}$

- OpenStreetMap

2. Buildings' information:

- Lombardia Beni Culturali ${ }^{18}$ - SIRBeC

- Students' projects from the course Preservation studio at Politecnico di Milano

- $\quad$ Literature (in the references)

- Historical cadastres (ASMi)

- Author's survey and interviews with locals

Additional documentation which includes private projects, surveys, photographs and illustrations are mostly collected by the author. Collecting material, specifically historical cartography, required the revision of the general historical facts and events which occurred in Vimercate for understanding the context in which some changes and events happened.

\section{QGIS project structure}

Organising collected materials in QGIS was an initial step which helped afterwards with the analysis of different material, from maps to texts (Figure 2). The project is divided into three main topics:

1. The ID of buildings - Point feature which stores all information about a single historical monument. This part of the project is called "project in deep" because it collects all the necessary data from official documents, students' projects, historical documentation, their presence in the historical maps and detailed descriptions (Figure 3).

2. Modern Maps - This group stores four different modern maps, among which was selected $\mathrm{DBT}^{19}$ as the one which provides the most accurate and complete data. This part of the project is called "project on the surface" because using the selected map as a base, the author searched for the traces of the past present nowadays (e.g. façade decoration, the old system of truss roof, historical courtyards, etc.) (Figure 4).

3. Historical Maps - This topic is divided into two subgroups, in the first are the maps of an urban scale $(1: 2000)$ and they are further vectorised so they could be easily compared one to another. The second subgroup is composed of maps that remained in the raster file which were useful for urban analysis.

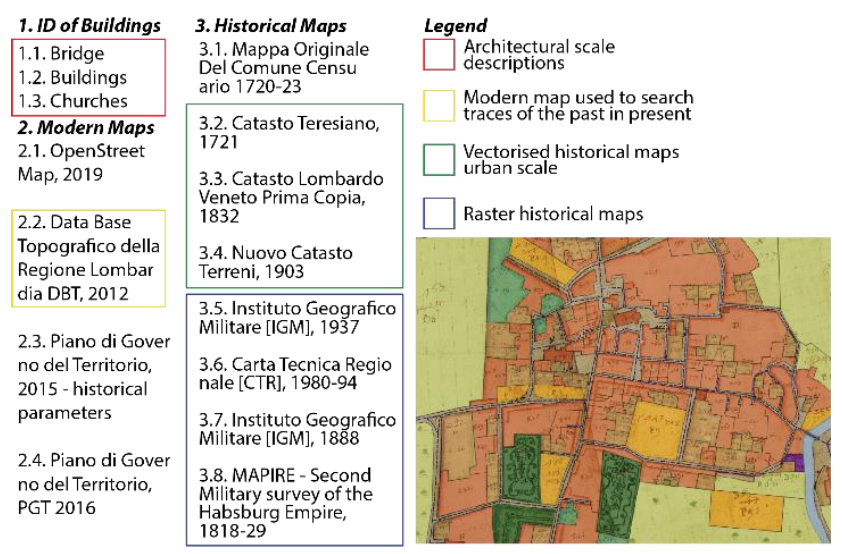

Figure 2. Structure of QGIS: Vectorized historical map; Author: Jovanovic, D.

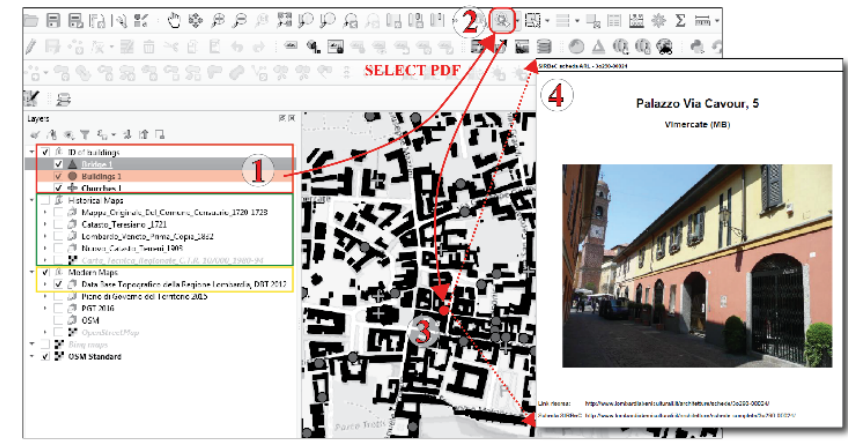

Figure 3. Structure of QGIS project and example of SIRBeC ${ }^{20}$ document integration in point features; Author: Jovanovic, D.

\footnotetext{
${ }^{12} \mathrm{http}: / /$ www.asmilano.it

${ }^{13} \mathrm{http}: / / \mathrm{www}$.geoportale.regione.lombardia.it

${ }^{14} \mathrm{https} / / /$ sportellotelematico.comune.vimercate.mb.it

${ }^{15} \mathrm{https}: / /$ mapire.eu/en/

${ }^{16} \mathrm{https}: / / \mathrm{www}$.igmi.org/
}

\author{
${ }^{17} \mathrm{http}: / /$ www.stagniweb.it \\ ${ }^{18} \mathrm{http} / / / \mathrm{www}$. lombardiabeniculturali.it \\ ${ }^{19}$ Data Base Topografico della Regione Lombardia, 2012 \\ ${ }^{20}$ Information System of Cultural Heritage of the Lombardy \\ Region, cataloguing of the Lombard cultural heritage.
}




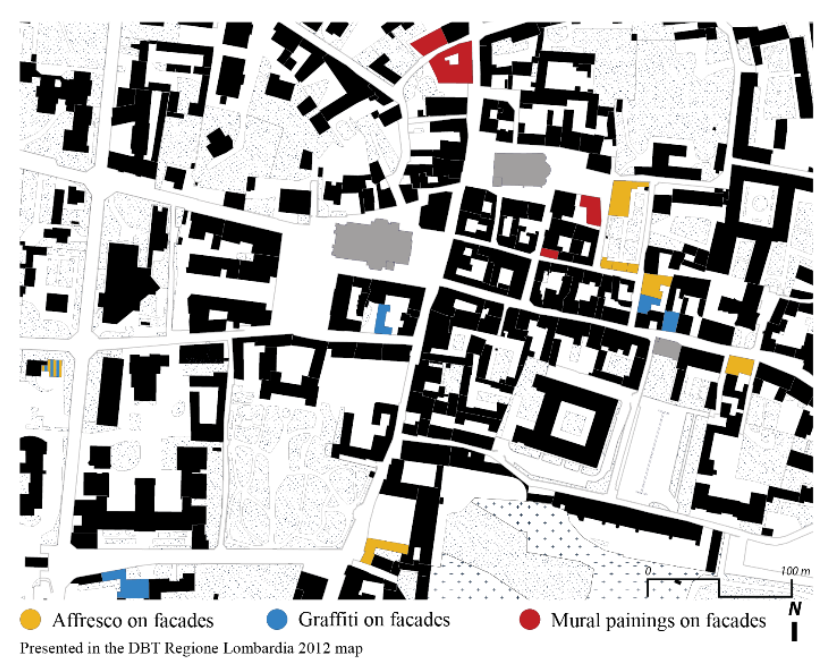

Figure 4. Thematic map, traces of the past today, façade decorations by using rule-based classification; Author: Jovanovic, D.

\section{Data processing}

\subsection{Non vectorised historical map}

\subsubsection{Mappa Originale del Comune Censuario -primo rilievo (1720-23) - Teresian Cadastre}

Mappa Originale del Comune Censuario di Vimercate was made as the first survey for Catasto Teresiano started in 1720 and finished in 1723. The map is drawn on a scale of 1:2000 and it has the notes and comments of the mapmaker which are visible in this big size map made on one sheet. The map was georeferenced and by doing so, it was possible to analyse the map profoundly. In literature could be found illustrations hypothesising the numbers and positions of gates of the town in the XII century which are non-existent today, except the one incorporated in the San Rocco bridge (Figure 5) (Penati 1957; Dossi and Crippa 1992). Nevertheless, investigating the historical map of 1720 the authors could detect seven gates and their positions in the town, which are reduced to the five presented in subsequent map Catasto Teresiano - beni di prima stazione from 1721.

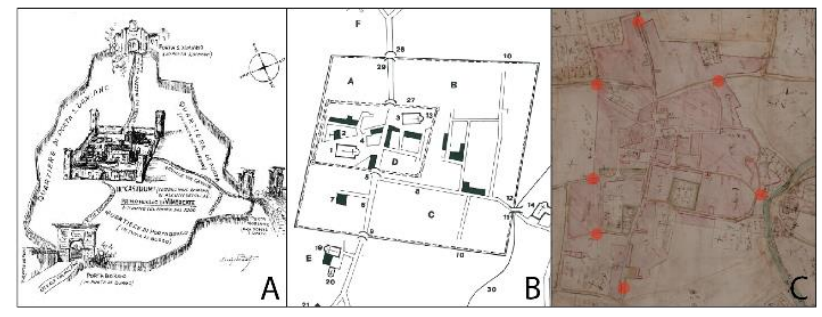

Figure 5. A) Penati's illustration (1957); B) Dossi and Crippa's illustration (1992); C) Mappa Originale del Comune (1720); source ASMi; Author: Jovanovic, D.

\footnotetext{
${ }^{21}$ Land cadastres of the first and the second station

${ }^{22}$ Engl. Municipality census

${ }^{23}$ Eng. Vimercate-Head of Parish Church

${ }^{24}$ Eng. in the same order: north, south, west, east
}

\subsection{Vectorized historical maps}

\subsubsection{Mappa di attivazione del Catasto Teresiano - beni di prima stazione (1721) and Catasto Teresiano - beni di seconda stazione $(1757)^{21}$}

Map Catasto Teresiano from 1721 drawn on a scale of 1:2000 was made to present agrarian fields, arable lands, vegetable gardens and built parcels. The aim of the map was not the shape of the buildings but was the property management for paying the taxes. Interestingly, the only buildings that were presented were churches, marked by letters. From the map and the title of the cadastre is evident that the church had religious importance, but also economic and administrative power. Descriptions found on the side of the maps' sheets of Mappa Catasto Teresiano - prima stazione are cadastral data, indicating the type of land, size, presence of trees and owners.

Around thirty years later was made Catasto Teresiano beni di seconda stazione and the authors included written land register made in 1757 of the comune censuario ${ }^{22}$ of Vimercate-Capo di Pieve ${ }^{23}$ to be compared with the cadastre from 1721. Compared data are almost identical, except that register had additional information describing the built parcels with the information about the owners, their origins, functions of the houses in the built parcels and their size, and description of neighbourhood parcels from four sides: tramontana, mezzogiorno, ponente, levante ${ }^{24}$. Dimensions of the parcels were expressed in pertiche and tavole ${ }^{25}$. Each built parcel had a number that can be related to the number on the map. Moreover, orti and giardini $i^{26}$ were described in the register and linked to the owner of the built parcels (Figure 6). Together, the cadastre written on the map and register produced in 1757 , create the complete image and an understanding that little has changed in between.

Catasto Teresiano - beni di prima stazione were the most detailed set of maps representing the use of the agrarian land and horticulture. The amount of details is mesmerising and that is why this map was vectorised in QGIS, so it could be connected to the written land register from Catasto Teresiano - beni di seconda stazione and analysed further. Each polygon of the lot has an attribute table filled with the additional metadata from both historical cadastres to be correlated. Transferring written text into the digital form allowed managing numerous thematical maps and rule-based classification (e.g. number and positions of the commercial services in the town, all land owned by the selected owner, number and positions of sacral architecture, etc.) (Figure 7).

25 Tavola is an ancient unit of measurement of surface, widespread in northern Italy, 24 tavole $=1$ pertica $=645,5 \mathrm{~m}^{2}$

${ }^{26}$ Eng. in the same order: vegetable gardens and gardens(parks) 


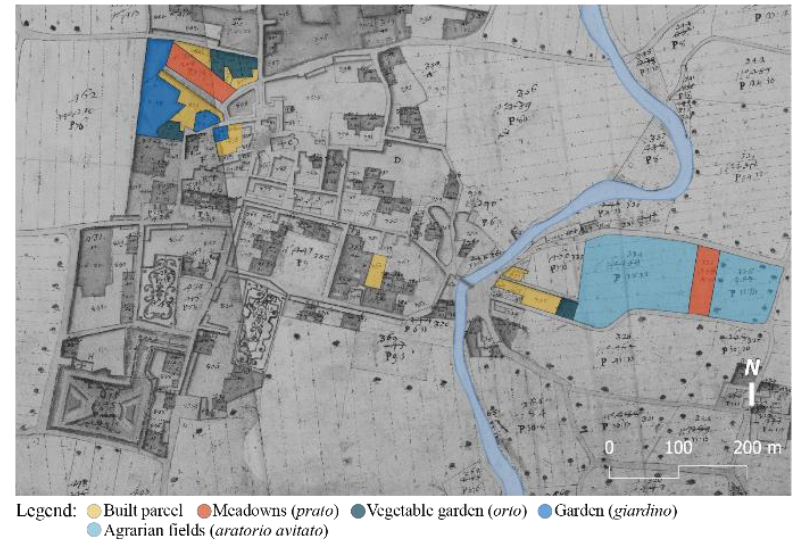

Figure 6. Land owned by Marquis Carcasola showed on the map by using rule-based classification; source ASMi; Author: Jovanovic, D.

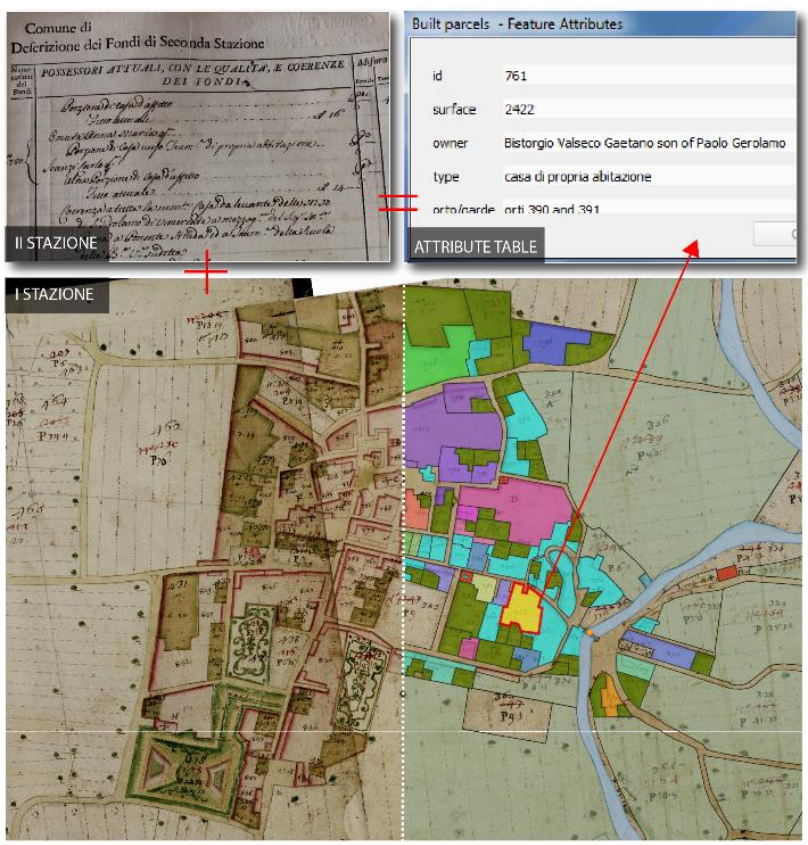

Figure 7. Vectorization of the Catasto Teresiano - beni di prima stazione (1721) and implementation of register of beni di seconda stazione in the attribute table; source ASMi; Author: Jovanovic, D.

\subsubsection{Mappa Lombardo-Veneto Prima Copia (1855)}

The map of Catasto Lombardo-Veneto started in 1855 and finished in 1873 drawn on a scale of 1:2000. For the first time could be seen the actual geometrical shape of the buildings. The parcel numbers are compared with the map Catasto Teresiano which was created more than a century before, and most of the numbers stayed the same, but some of the building changed their function (Figure 8). The map focuses primarily on the buildings in such a way that there is a devoid of all other details, like the use of agrarian fields in the previously mentioned map. Vectorising the map lead to the discovery of the wells, from which one remained present today and could be found in via Cavour, inside the real estate office (Figure 9). Overlapping the georeferenced maps Catasto Tresiano (1721) and Catasto
Lombardo-Veneto (1855) it is evident that there was a change in the blocks' composition and streets' disposition. With the comparison, it is visible that the city started sprawling to the north side of the town in form of smaller residential dwellings.

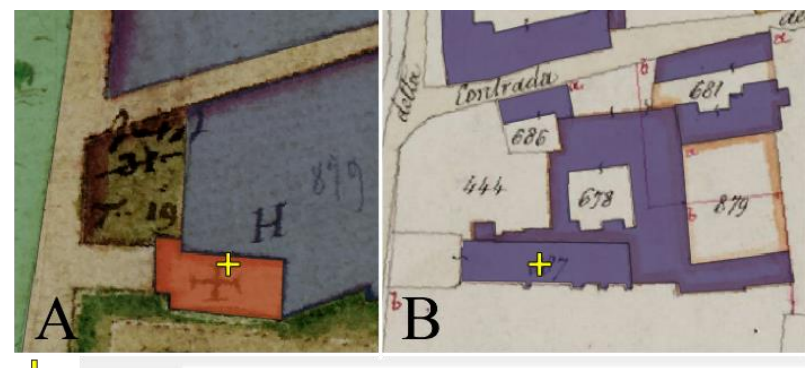

S Name Chiesa si S. Francesco with convent monastery

$$
\begin{aligned}
& \text { A } 1721 \text { map yes } \\
& \text { B } 1855 \text { map no }
\end{aligned}
$$

Figure 8. Church in map A) Catasto Teresiano and not in map B) Lombardo-Veneto, attribute table of "ID of buildings" point layer; source ASMi; Author: Jovanovic, D.

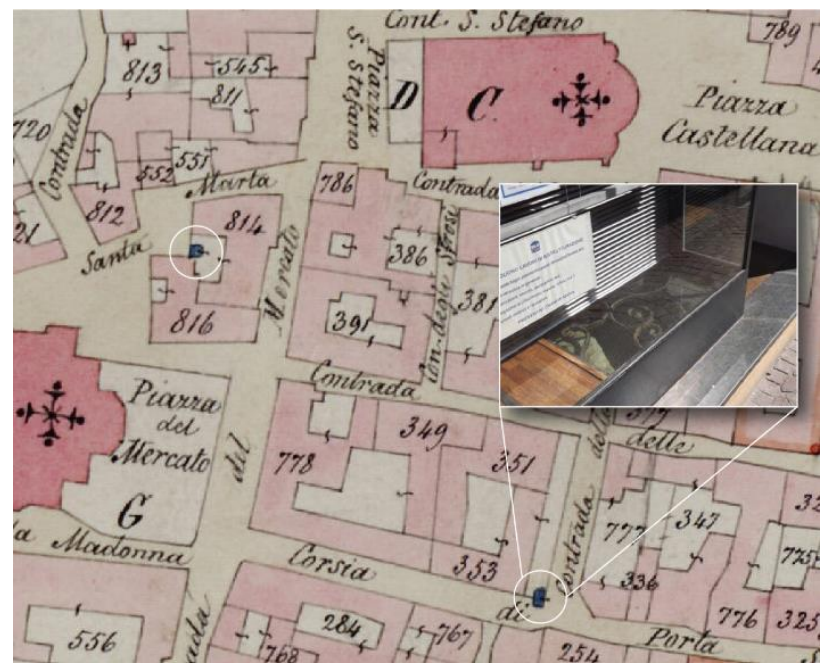

Figure 9. Presentation of the only remained well on the map Catasto Lombardo-Veneto Prima Copia (1855); source ASMi; Author: Jovanovic, D.

\subsubsection{Mappa Nuovo Catasto Terreni (1902)}

The production of map Nuovo Catasto Terreni was started in 1897 and was finished in 1902 drawn on a scale of 1:2000. There are no considerable changes in the built environment in the historical centre, but one phenomenon is widespread. If compared with the map of Lombardo Veneto (1855) it could be detectable that the form of villa changed. Through this map could be investigated the general type of Lombardian villa. During the XVI century built as the mono-block structure progressively tended to open towards the external environment, to the public street, firstly though large and tall open galleries and then breaking the quadrilateral plan to make a U-shape plan with portico elements (Vv. Aa. 1997). Villa that was open to the street now starts to have additions in the form of monumental gates or even buildings that will close the 
view from the street and secure private courtyard (Figure 10). Additionally, the town started sprawling even more in each direction. Considerable increase in the buildings' construction happened after the bridge San Rocco on the east side of the riverbank and the south-east of the city centre.

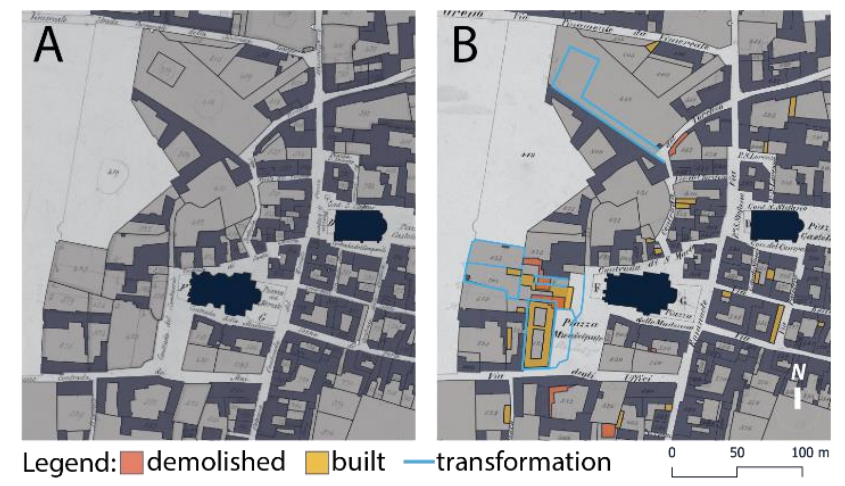

Figure 10. Changes in block structure and villa transformation from A) Catasto Lombardo-Veneto (1855), digitalised map to the B) Nuovo Catasto Terreni (1902), digitalised map; source of historical maps ASMi; Author: Jovanovic, D.

\subsection{Raster maps - rapid expansion of Vimercate}

For the period from 1721 to 1903 , changes in the urban area of Vimercate were slight and more in the form of construction of single residential houses or farmhouses in the periphery. In the next thirty years, the city expanded more than for the previous two hundred. In the map Istituto Geografico Militare (IGM) from 1937 drawn on a scale of 1:10.000, is visible that sprawl boomed. This can be associated with the development of the industrial sector in the town, an increase in economic requirements and the need for travel. The plans for big neighbourhoods were executed. During this period municipalities of Vimercate, Oreno, Oldaniga and Ruginello merged into a single urban area almost indistinguishable.

Throughout the XIX and the XX century, one novelty appeared, and it is readable in the maps: construction of villas on the periphery of the town with big gardens. Villa no longer had an interaction with the surrounding but used the garden as the barrier to create enclosed space $^{27}$. Nevertheless, the historical city centre remained almost intact, with the minor changes inside this most sensitive urban tissue.

The biggest changes in the historical centre are noticeable in the map Carta Tecnica Regionale (CTR) made between 1980 and 1994 drawn on a scale of 1:10.000. Few multistorey buildings were incorporated in the historical centre without respecting the context and some other historical buildings were demolished to make space for the commercial centres or parking lots.

\section{Education and participatory activities of the stakeholders}

Effective application of the thesis project started in the courses of Architectural preservation studio at Politecnico di Milano. This was followed by the interest of citizens in the project who were actively participated in the creation of the same. Other stakeholders showed interest in involving in future developments.

\subsection{Support for education and lectures}

The thesis was presented up until now more than a dozen times on a masters and bachelors studios of Architectural preservation studios at Politecnico di Milano, to about more than 350 students, as a far-reaching example of managing a vast historical database, including historical maps and cadastres.

Through the demonstration of the project, students learn about the application of the software for collecting knowledge and for the enhancement of cultural heritage. They gain the necessary technical skills to contribute further and develop their projects. Regardless, the students can use the thesis project as the database where the knowledge about Vimercate's urban development was collected. Investigating the historical cartography together, the following steps of collecting, managing and georeferencing the selected maps are also part of the education and training of young professionals. Finally, teaching about critical thinking is crucial when it comes to the study of historical documents.

Educating them through this example demonstrates how to use historical cartography together with the modern maps and contemporary data in open and free source software QGIS for the development of the urban analysis, but also as an important tool for architectural scale studies.

Collecting final students' works is an important contribution to the project's database because they are on the independent and unbiased side of the research and their work might not be always correct, it is still important to be critically analysed and transparently presented to a wider range of stakeholders.

\subsection{Local conference}

The thesis was presented in the conference Sagra di Sant'Antono 2020 in Vimercate on the theme: "Between historical and digital paths: Ways of knowing the centre of Vimercate", in the organization of ProLoco di Vimercate (Professors Rossella Moioli and Stefano Della Torre).

\footnotetext{
${ }^{27} \mathrm{http}: / / \mathrm{www}$. lombardiabeniculturali.it/percorsi/villemilano/1.2/
} 
After the presentation, there was an open discussion and with almost eighty inhabitants participating and suggesting how the project could be developed and improved further.

\subsection{Event for pupils in Vimercate}

During the festival "Vimercate Ragazzi Festival" held in Vimercate in June 2019, ProLoco di Vimercate made an event called Treasure hunt: "Discovering the past". Together with the high-school students, we created an itinerary map for elementary pupils of the cultural heritage of Vimercate, using the database created for the thesis.

The GIS database was used to produce the map which served for the event and presented information about cultural heritage in the city centre (Figure 11). Furthermore, creating digital GeoDB showed as the most efficient way to manage historical data together with the contemporary, because even if the project was not built for the tourist-like maps, it gives the possibility of producing various thematic maps which could be understandable to anyone.

Interactive events between different generations resulted in gathering the community, from the youngest to the oldest, about what are their common cultural goods. Educating the youngest about their cultural heritage, showing them the importance of understanding and respecting it, will create a new generation of responsible young people recognising the values of their surroundings. Moreover, kids learn how to use and read maps thought fun.

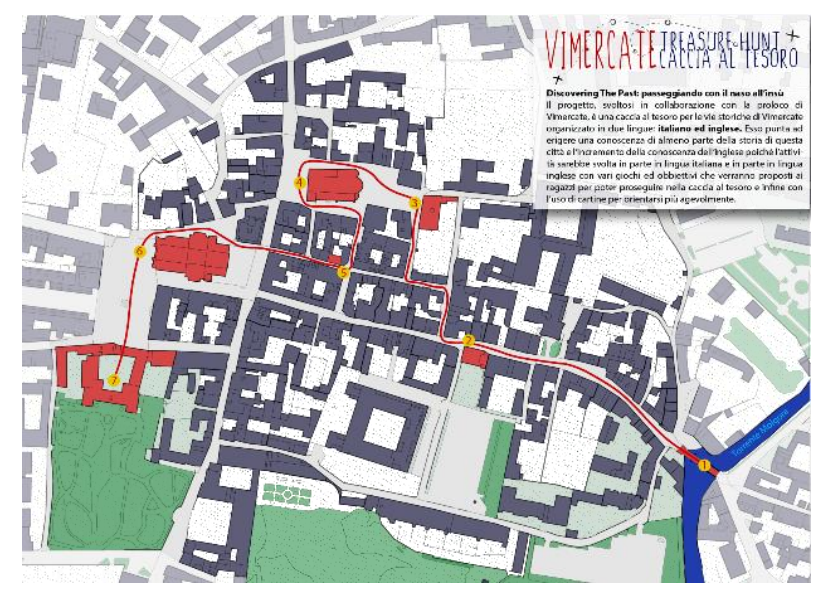

Figure 11. Frontpage of the map for pupil's event "Discovering the Past"; Author: Jovanovic, D.

\subsection{Collaboration with local administration}

The thesis was presented to the officials from the MUST Museum in Vimercate and to the Municipality of Vimercate, as an idea of the interactive learning platform, which will connect sides at the institutional level (i.e. Politecnico di Milano with Municipality of Vimercate) and the individual level (i.e. university students with citizens). Officials showed interest in participating in the conference Sagra di Sant'Antono 2020 because the project is also useful as an administrative tool, which gives it considerable importance (Figure 12).

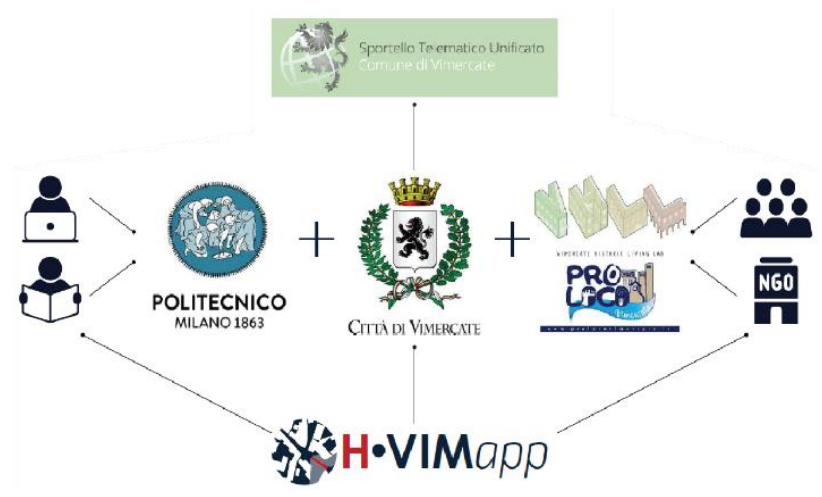

Figure 12. Connection of stakeholders, their contribution to the project and possible outcome creating the WebGIS to be used as the administrative tool; Author: Jovanovic, D.

\subsection{Citizens' participation: Online and Face-to-Face}

Engagements and the interests of the citizens in the cultural heritage of Vimercate are evident through their participation in social networks, events and festivals. This attitude and curiosity towards the city are incredibly important, which leads to better understanding values and prevent possible vandalisation. For example, the Facebook group "Cartoline di Vimercate" 28 united citizens interested to participate and share their photos and knowledge about the history of Vimercate.

Similarly, the Facebook group called "Vimercate Historic Living Lab"29 was initiated and guided by the professors from Politecnico di Milano to gather people who are interested in the history of Vimercate. Besides, this is the first attempt to share some of the students' works publicly with non-professionals.

Participation of the local community was tremendous, and they greatly contributed to this project. They shared their audible mental maps of memories and stories, followed by the private photographs and illustrations inherited from their ancestors. Spoken information is just a trigger for further research about the actual historical fact, which should be a prior element for a well-proven analysis. Interestingly, stories behaved as imaginative maps, walking around with the people showing their property and pointing out to the parts of the building which did not change for centuries, created map itself. The goal of the author was to transfer these mental images and narrations into the actual visual map. 


\section{Future work}

It is significant to appoint some questions and problems for further development of this project:

- There is a significant lack of information about Vimercate in Roman times.

- Collecting more information on an architectural scale about single buildings.

- Since only historical cadastre analysed, translated and vectorised in the attribute tables was Catasto Teresiano (1757) the future work would be adding other historical cadasters.

- Constant reviewing and a critical attitude towards the discovered data are crucial.

- The most important goal of this project is to be free, open and available to anyone. Hopefully, in the future, the project will be available online for a consultation.

\section{Conclusion}

The aim of the thesis project was not to create simple storage of historical data but to show the power of the HGIS, the importance of interactive mapping and analyses of historical cartography. Additionally, the thesis is an example of how cartography is not limited just to maps, but there are other documents and materials which could help us to better understand the map itself and what the map is showing to us. Georeferencing and vectorising historical maps inside one system allowed the author to discover new data about the city and to profoundly understand the urban change. Overcoming the attitude of looking at the single building but shifting the focus on the whole urban context firstly, creates a fertile ground of information for preservation projects. The main goal was to contribute to the wider scientific knowledge by increasing and reinforcing public awareness of different stakeholders towards the cultural heritage of Vimercate so they could be able to work together in protecting and maintaining their common heritage.

The thesis was used as a teaching tool, showing the possibilities of QGIS as software, and historical cartography and contemporary data to the masters' and bachelor student at Politecnico di Milano, which was proved to be the best way to teach - through example.

Finally, the local community created mental maps and was participating actively in the development of the thesis. Presenting the project educates non-professional about historical cartography, not just as an artistic artefact, but also as a valuable source of information for a wide range of application, from architecture to territorial management and planning.

\section{Acknowledgements}

Many thanks to architect Matteo Villa for his support and guidance in Vimercate. Thanks to students from Politecnico di Milano sharing their projects with me, and finally great gratitude is shown to the inhabitants of Vimercate.

\section{References}

Brumana, Raffaella, Branka Cuca, Daniela Oreni, F Prandi, and Marco Scaioni. 2010. "Integration of Old Cadastral Maps into Up-to-Date Geodatabases for Urban Planning." The International Archives of the Photogrammetry, Remote Sensing and Spatial Information Sciences, 90-95.

Cazzani, Eugenio. 1975. Storia Di Vimercate. Edizioni Artegrafica," Luigi Penati e Figli".

Della Torre, Stefano, Rossella Moioli, and Lorenzo Cantini. 2018. "The Historic Centre of Vimercate: Investigation, Education, Community Involvement." In , 319-28. Springer.

Dossi, Sergio, and Stefano Crippa. 1992. Vimercate Medievale: Storia, Civiltà e Vita, Attraverso $i$ Suoi Monumenti. Vimercate: I libri del gabbiano.

Gianoncelli, Matteo, and Stefano Della Torre. 1984. "Microanalisi Di Una Città. Proprietà e Uso Della Città Murata Di Como Dal Cinquecento All'Ottocento." Editore New Press, Como, Italia.

Huffman, Kristin L, Andrea Giordano, and Caroline Bruzelius. 2017. Visualizing Venice: Mapping and Modeling Time and Change in a City. Routledge.

Nevola, Fabrizio, and David Rosenthal. 2016. "Locating Experience in the Renaissance City Using Mobile App Technologies: The 'Hidden Florence' Project,' in Mapping Space, Sense, and Movement in Florence: Historical GIS and the Early Modern City." Mapping Space, Sense, and Movement in Florence: Historical GIS and the Early Modern City, 187.

Penati, L. 1957. Vimercate. Raccolta Di Notizie Storiche. L. Penati, Vimercate.

Riscica, Rossella, and Chiara Voltarel, eds. 2017. Treviso Urbs Picta. Facciate Affrescate Della Città Dal XIII al XXI Secolo: Conoscenza e Futuro Di Un Bene Comune. Treviso, Italia: Fondazione Benetton Studi Ricerche-Antiga Edizioni.

Roders, Ana Pereira, and Francesco Bandarin. 2019. Reshaping Urban Conservation: The Historic Urban Landscape Approach in Action. Vol. 2. Springer.

Venturelli, Paola, and Graziano Alfredo Vergani. 1998. Mirabilia Vicomercati: Itinerario in Un Patrimonio d'arte: L'età Moderna. Venezia: Marsilio.

Vergani, Graziano Alfredo, ed. 1994. Mirabilia Vimercati: Irinerario in Un Patrimonio d'arte: Il Medioevo. Venezia: Marsilio.

Vv. Aa. 1997. La Villa Lombarda, Luogo Di Lavoro e Di Delizia. Zonta Club Milano I, La grafica Arlunese. 